\title{
Apoptosis signal-regulating kinase 1 is associated with the effect of claudin- 6 in breast cancer
}

\author{
Yaxiong Guo', Xiaoming Xu², Zhijing Liu', Ting Zhang ${ }^{1}$, Xiaowei Zhang ${ }^{1}$, Liping Wang ${ }^{1}$, Min Wang ${ }^{1}$, \\ Yuanyuan Liu', Yan Lu', Yunpeng Liư and Chengshi Quan ${ }^{3 *}$
}

\begin{abstract}
Background: Previous studies have demonstrated that claudin-6 functions as a cancer suppressor in human MCF-7 breast cancer cells. The growth inhibitory effect could be attributed to inhibition of cell proliferation and induction of apoptosis. The purpose of the current study was to examine the involvement of apoptosis signal-regulating kinase 1 (ASK1) in the anticancer effect of claudin-6.

Methods: Immunohistochemical analysis was performed to evaluate the ASK1 protein expression and the correlation between ASK1, claudin-6 and clinicopathological features in 85 samples of breast invasive ductal carcinomas (IDC). Western blotting and RT-PCR was carried out to examine the expression of ASK1 and claudin-6 in MCF-7 cell clones transfected with claudin-6.

Results: Immunohistochemical analysis showed that ASK1 expression was significantly related with that of claudin-6 in breast invasive ductal carcinomas $(P<0.05)$. In addition, a positive correlation between ASK1 and C-erb B 2 protein expression was identified $(P<0.05)$. Western blotting and RT-PCR consistently revealed that the level of ASK1 protein and mRNA was upregulated in MCF-7 cell clones transfected with claudin-6.
\end{abstract}

Conclusions: Our data suggests, for the first time, that the ASK1 signal may play a positive role in the inhibitory effect of claudin-6 in breast cancer.

Virtual Slides: The virtual slide(s) for this article can be found here: http://www.diagnosticpathology.diagnomx.eu/ vs/1200314318763661

Keywords: Breast invasive ductal carcinomas, ASK1, Apoptosis, Tight junction

\section{Background}

Breast cancer is one of the most frequent and deadly cancers in women [1]. Emerging evidence points toward a pivotal role of tight junction (TJ) in mediating tumorigenic growth of breast cancer $[2,3]$. TJs are junctional complexes which mediate cell-to-cell adhesion in epithelial and endothelial cellular sheets [4], and which affect cell polarity and tight junction formation [5].

Claudins (CLDNs) constitute a family of integral membrane proteins and have been identified as prominent structural components of TJ strands [5,6]. The CLDNs which include 27 members at least [7], encode 20-27 $\mathrm{kDa}$ proteins with four transmembrane domains and

\footnotetext{
*Correspondence: clondy_123@163.com

${ }^{1}$ The Key Laboratory of Pathobiology, Ministry of Education, Beyuthune Medical College, Jilin University, Changchun, Jilin, China

Full list of author information is available at the end of the article
}

two extracellular loops [8]. The expression of CLDNs is often different in various types of human tumor $[9,10]$. Many studies have demonstrated that claudins may participate in several signal transduction pathways [11-15]. For instance, inhibition of c-jun NH2-terinal kinase (JNK) and p38 mitogen-activated protein kinase (p38 MAPK) selectively modulates the expression of claudin$4,-8$ and -9 to enhance TJ barrier function in mammary epithelial cells [16], And p38 MAPK activity is involved in the epithelial barrier dysfunction in which claudin-7 protein plays a major role [17]. It is well known that apoptosis signal-regulating kinase 1 (ASK1) phosphorylates and actives both p38 and JNK pathway [18]. ASK1 is a member of the MAPKKK family and functions as a promoting apoptosis gene in response to common proapoptosis stresses [19]. However, there is little

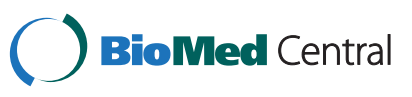


knowledge about the relationship of ASK1 and claudins, especially claudin-6.

In our previous study, we found that claudin- 6 is preferentially expressed in mammary epithelial cells and functions as a potential breast cancer suppressor gene [20], which is supported by the follow-up study of Osanai [21]. Recently, we have discovered that the low level expression of claudin- 6 gene contributed to malignant progression of breast cancer [22]. A previous study has described that breast cancer tissues also expressed lower levels of ASK1 compared with normal mammary tissues [23]. Therefore, the purpose of the current study is to discover the relationship between ASK1 and claudin- 6 in breast cancer and to explore the pathways involves the activation of ASK1.

\section{Methods}

Patients and tissue samples

The breast samples were obtained from 2006-2010 in the Jilin Oil Field General Hospital in Songyuan, Jilin province, China. A total of 85 breast invasive ductal carcinomas (IDC) aged 26 to 77 with a mean age of 51 were included in this study. The study was approved by the Ethics Committee of Jilin University. Clinicopathological features of 85 IDC samples are summarized in Table 1.

\section{Cell culture}

Human breast cancer cell line MCF-7 cell clones expressing an vector pcDNA3.1 (+) or claudin- 6 were cultured as previously described [22].

\section{Quantitative RT-PCR}

Total RNA was extracted from clone cells using TRIzol (Invitrogen, USA) following the manufacturer's instructions. One microgram of total RNA was subjected to reverse transcription to synthesize cDNA using the M$\mathrm{MuLV}$ reverse transcriptase (TaKaRa, Japan) at $42^{\circ} \mathrm{C}$ for 1 hour, and 0.5 ug cDNA was used for PCR. ASK1 and claudin- 6 were amplified along with GAPDH as an endogenous control following the instructions of Premix LA Taq Kit (TaKaRa, Japan). The PCR reaction conditions and the primer sequences of ASK1, claudin- 6 and GAPDH are shown in Table 2. After electrophoresis, the gel was captured and analyzed by the image system (Syngene, Cambridge, UK).

\section{Western blotting analysis}

The Western blotting analyses were performed as described previously [22]. Primary antibodies included ASK1 (rabbit polyclonal antibody, 1:1000, Bioworlde Technology), claudin-6 (rabbit polyclonal antibody, 1:1000, Bioworlde Technology) and $\beta$-actin (mouse polyclonal antibody, 1:1000, Santa Cruz). Secondary antibodies for the detection: anti-rabbit IgG (1:2000,
Table 1 Clinicopathological features and the expression of ASK1 in 85 IDC samples

\begin{tabular}{|c|c|c|c|c|c|}
\hline \multirow{2}{*}{$\begin{array}{l}\text { Clinicopathological } \\
\text { features }\end{array}$} & \multirow[t]{2}{*}{ Cases } & \multicolumn{2}{|c|}{ ASK1 expression (n) } & \multirow[t]{2}{*}{$x^{2}$} & \multirow[t]{2}{*}{$P$} \\
\hline & & Positive & Negative & & \\
\hline Age (years) & & & & 0.017 & 0.896 \\
\hline$\geq 45$ & 58 & 18 & 40 & & \\
\hline$<45$ & 27 & 8 & 19 & & \\
\hline Histological grade & & & & 0.668 & 0.414 \\
\hline $\mid \sim \|$ & 21 & 8 & 13 & & \\
\hline III & 63 & 18 & 45 & & \\
\hline Tumor size & & & & 0.21 & 0.646 \\
\hline$\geq 5 \mathrm{~cm}^{3}$ & 66 & 21 & 45 & & \\
\hline$<5 \mathrm{~cm}^{3}$ & 19 & 5 & 14 & & \\
\hline Lymph node metastasis & & & & 0.527 & 0.468 \\
\hline Positive & 41 & 11 & 30 & & \\
\hline Negative & 44 & 15 & 29 & & \\
\hline TNM stage & & & & 0.336 & 0.562 \\
\hline $1, \|$ & 55 & 18 & 37 & & \\
\hline$\| I I, I V$ & 30 & 8 & 22 & & \\
\hline Lesion location & & & & 2.406 & 0.121 \\
\hline Right & 45 & 10 & 35 & & \\
\hline Left & 34 & 13 & 21 & & \\
\hline ER & & & & 0.105 & 0.746 \\
\hline Positive & 37 & 12 & 25 & & \\
\hline Negative & 48 & 14 & 34 & & \\
\hline PR & & & & 0.425 & 0.515 \\
\hline Positive & 38 & 13 & 25 & & \\
\hline Negative & 47 & 13 & 34 & & \\
\hline C-erb B-2 & & & & 5.747 & 0.017 \\
\hline Positive & 27 & 13 & 14 & & \\
\hline Negative & 58 & 13 & 45 & & \\
\hline
\end{tabular}

Statistical analyzed by Pearson's chi-square test.

Proteintech Group) and anti-mouse IgG (1:2000, Proteintech Group).

\section{Immunohistochemistry}

Immunohistochemical staining was carried out as described in our previouspublications [24]. The primary antibodies against ASK1 (rabbit polyclonal antibody, 1:200, Bioworlde Technology) and claudin-6 (rabbit polyclonal antibody, 1:200, Bioworlde Technology) were used. The negative controls were handled in the same way except PBS instead of primary antibody.

Positive-staining exhibits brown staining, Claudin- 6 was shown on the cell membrane and/or cytoplasm in breast cancer tissues [24], and ASK1 expressed on the breast cancer cytoplasm according to the manufacturer's Instructions of ASK1 antibody. Immunostaining was 
Table 2 Primers used for PCR

\begin{tabular}{|c|c|c|c|c|c|}
\hline Gene & & Sequence of primers & Size of PCR(bp) & Denaturation temperature $\left({ }^{\circ} \mathrm{C}\right)$ & Cycles \\
\hline \multirow[t]{2}{*}{ ASK1 } & sense & 5'-TTCACACAAAACGGATGTAACATT-3' & 198 & 56 & 30 \\
\hline & antisense & 5'-CCTAAACAGTTATGGTCACATTTTGG-3' & & & \\
\hline \multirow[t]{2}{*}{ Claudin-6 } & sense & 5'-TTCATCGGCAACAGCATCGT-3' & 345 & 58 & 35 \\
\hline & antisense & 5'-GGTTATAGAAGTCCCGGATGA-3' & & & \\
\hline \multirow[t]{2}{*}{ GAPDH } & sense & 5'-TGTTGCCATCAATGACCCCTT-3' & 202 & 56 & 25 \\
\hline & antisense & 5'-CTCCACGACGTACTCAGCG-3' & & & \\
\hline
\end{tabular}

observed under light microscopy with 400x magnification, and positive cells, negative cells and total cells of five different visual fields were numbered in each specimen. Scoring was performed as follows: negative (-), $<10 \%$ positive tumor cells; positive $(+), \geq 10 \%$ positive tumor cells.

\section{Statistical analyses}

All computations were carried out using the software of SPSS version 19.0 for Windows (SPSS Inc, IL, USA). Chi-Square test was used to examine categorical data. Unpaired t-tests were performed to evaluated data of target mRNA and protein. The data are presented as means \pm standard deviation (SD) from at least three independent experiments. $\boldsymbol{P}<0.05$ was considered statistically significant.

\section{Results}

\section{Association of ASK1 expression with the} clinicopathological features of breast invasive ductal carcinomas

The clinicopathological characteristics of the patients are summarized in Table 1 . In order to investigate whether ASK1 protein expression was associated with clinicopathological features of patients of breast cancer, we correlated immunohistochemical ASK1 staining results with clinicopathological features. In this study, ASK1 protein was evaluated in the cytoplasm of breast cancer (Figure 1A), and the positive expression of ASK1 protein was found in 30.59\% (26/85) of breast IDCs. ASK1 protein expression had no correlation with age $(\boldsymbol{P}=0.896)$, histological grade $(\boldsymbol{P}=0.414)$, tumor size $(\boldsymbol{P}=0.646)$, lymph node metastasis $(\boldsymbol{P}=0.468)$, TNM stage $(\boldsymbol{P}=0.562)$ and lesion location $(\boldsymbol{P}=0.121)$. But interestingly, we found that ASK1 had relationship with $\mathrm{C}$-erb B 2 protein expression $(\boldsymbol{P}=0.017)$.

Correlation between the expression of ASK1 and claudin6 in breast cancer tissues

We have found that the expression of claudin- 6 was reduced in breast invasive ductal carcinomas [24]. The expression of claudin-6 (Figure 1A, 1B) and ASK1 (Figure 2A, 2B) was examined by immunohistochemistry, and the correlation between claudin- 6 and ASK1 was analyzed by Pearson's chi-square test. As shown in Table 3, the positive expression rate of claudin- 6 was $27.09 \%(23 / 85)$ in IDC specimens, and cells were positive for ASK1 in $30.59 \%(26 / 85)$ of IDC cases. Half $(13 / 26)$ of the ASK1 positive cases were positively staining for claudin-6, but only $16.95 \%$ (10/59) of ASK1 negative cases stained positively for claudin-6. Statistical analysis revealed that claudin- 6 expression was positive correlated with ASK1 expression in breast invasive ductal carcinomas $(\boldsymbol{P}=0.0016)$.

\section{Correlation between the expression of claudin- 6 and ASK1 in breast cancer cells}

We found the correlation between claudin- 6 and ASK1 expression in breast invasive ductal carcinomas tissues, but their relationship in breast cancer cell line was unknown. We used MCF-7 cells transfected with pcDNA3.1 (+) and three G418 resistant MCF-7 clones,

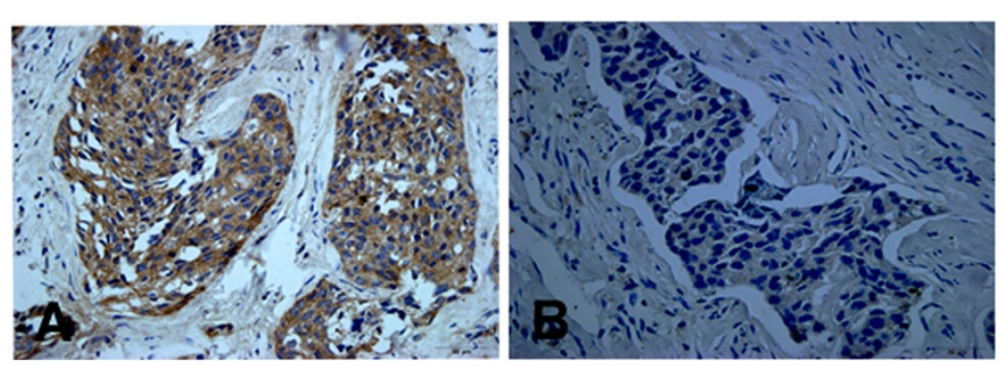

Figure 1 Expression and location of ASK1 in breast invasive ductal carcinoma (IDC) (Original magnification $\times$ 400). (A) ASK1 positive staining was predominant in the cytoplasm of breast carcinoma tissues. (B) ASK1 negative staining was seen in IDC tissues. 


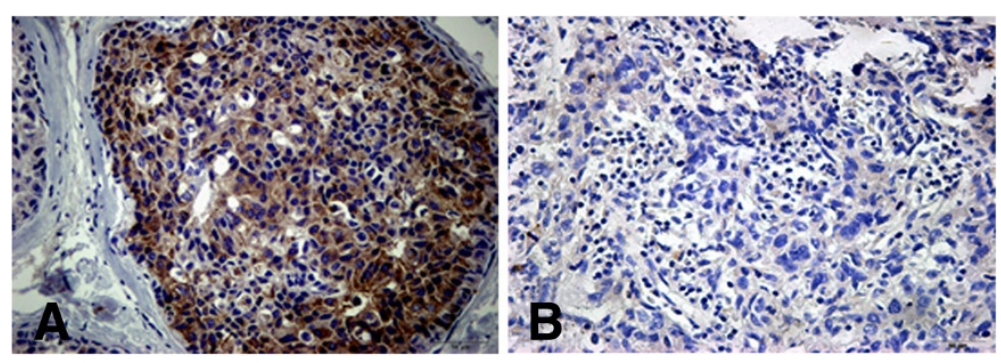

Figure 2 Expression and location of claudin- 6 in breast invasive ductal carcinoma (IDC) (Original magnification $\times 400$ ). (A) Claudin-6 was expressed in the membrane and cytoplasm of IDC tissues. (B) Claudin- 6 was weakly expressed in IDC tissues.

which expressed claudin-6 stably. When claudin-6 was upregulated, ASK1 had a higher expression level than that in empty vector group (Figure 3A, 3C). Quantitative RT-PCR and western blot analysis showed that the level of claudin- 6 mRNA and protein positively correlated with the level of ASK1 mRNA and protein (Figure 3B, 3D).

\section{Discussion}

In the previous study, We found that the expression level of claudin- 6 was lower in two human breast cancer cells (MCF-7 and BT474) and one breast cancer sample than that in normal breast tissues [20]. In addition, we also discovered the growth, migration and invasion of MCF-7 cells were inhibited by overexpression of claudin-6 [22]. One report has shown that the expression of ASK1 is lower in breast cancer tissues than that in normal tissues [23]. As we all known, ASK1 is regulated in response to various cellular stresses, including cell survival, proliferation, differentiation, and so forth. Therefore, in the current study, we attempted to elucidate the relationship between the expression of claudin- 6 and ASK1 using clinicopathological features and classical prognostic factors in breast pathology, including the expression of immunohistochemical markers of prognostic significance (ER, PR, C-erb B 2) (Table 1). To the best of our knowledge, this is the first study to demonstrate an association between the protein expression of claudin- 6 and ASK1 in a large series of breast invasive ductal carcinomas and the breast cancer cells.

We have previously found that the expression of claudin-6 was negatively correlated with lymphatic metastasis of breast IDCs [24], but we did not found the correlation between ASK1 expression and the lymphatic metastasis (Table 1). This may be mainly due to that the ASK1 signal pathway is not the only pathway to be regulated by claudin- 6 . Besides that, we found the correlation of claudin- 6 and $\operatorname{ER} \alpha(p=0.033)$, and also discovered that ER $\alpha$ regulated claudin-6 in MCF-7 cells [25]. We failed to find the correlation between ASK1 and ER. And the reason high likely is the cross-talk among different signaling pathways, as we discussed in the case of failing to discover the correlation of ASK1 and lymphatic metastasis. However, we revealed the correlation between ASK1 and C-erb B 2 (Table 1). These results indicate the role of C-erb B 2 in ASK1 signal pathway. We next analyzed the relationship of C-erb B 2 and claudin-6, but we found no relationship between them (data not shown). Therefore, these data suggest that the inhibitory effect of claudin-6 in breast cancer mainly results from the regulation of ASK1.

Besides analysis of the breast cancer tissues, we also analyzed the correlation of ASK1 and claudin- 6 mRNA and protein in breast cancer cell lines. We have found claudin-6 was a anti-cancer gene in claudins family [22], and the up-regulation of claudin- 6 has important clinical implication, but details of the mechanism was not clear. C-jun NH2-terinal kinase (JNK) and p38 mitogenactivated protein kinase (p38 MAPK) signal pathway played a positive role in the process of claudin- $4,-8$ and -9 enhancing TJ barrier function in mammary epithelial cells [16]. ASK1 actives JNK and p38 pathway and induces apoptosis in various cells through mitochondriadependent caspase activation [18,26-28]. ASK1

Table 3 The correlation between the expression of claudin-6 and ASK1 in breast invasive ductal carcinomas

\begin{tabular}{|c|c|c|c|c|c|}
\hline \multirow[t]{2}{*}{ ASK1 expression } & \multirow[t]{2}{*}{ Cases $(\mathbf{n}, \%)$} & \multicolumn{2}{|c|}{ Claudin-6 expression ( $n, \%)$} & \multirow[t]{2}{*}{$x^{2}$} & \multirow[t]{2}{*}{$P$} \\
\hline & & Positive & Negative & & \\
\hline Positive & $26(30.59 \%)$ & $13(50 \%)$ & $13(50 \%)$ & 9.988 & 0.0016 \\
\hline Negative & $59(69.41 \%)$ & $10(16.95 \%)$ & $49(83.05 \%)$ & & \\
\hline Case (n) & $85(100 \%)$ & $23(27.09 \%)$ & $72(72.01 \%)$ & & \\
\hline
\end{tabular}

Statistical analyzed by Pearson's chi-square test. 
A

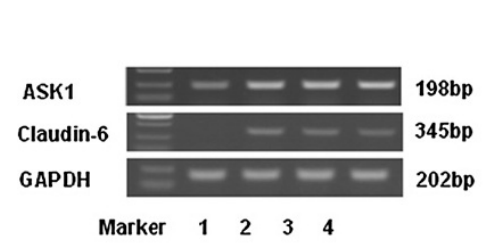

C

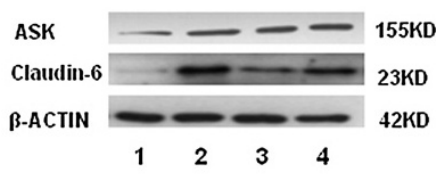

B

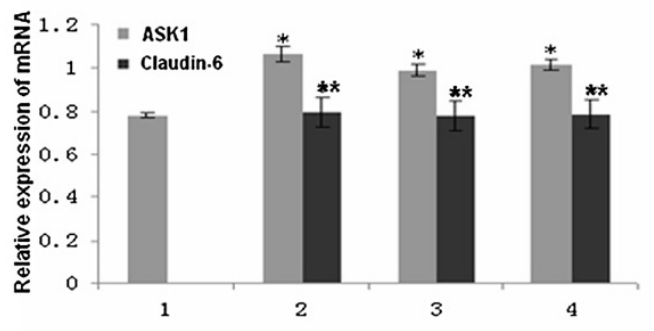

D

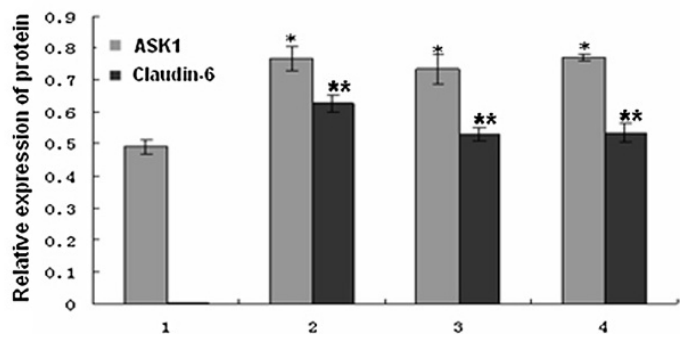

Figure 3 Correlation of claudin-6 and ASK1 in breast cancer cells. Line 1 is empty vector group; lines 2, 3 and 4 are three clone groups. (A) (B) RT-PCR assay examined the mRNA levels of claudin-6 and ASK1. (C) (D) Western blot assay detected claudin-6 and ASK1 protein expression. ${ }^{*},{ }^{* *} P<0.05$, vs. vector group. Results are means \pm standard deviation for three independent experiments.

activation depends on its binding proteins such as TNF receptor-associated factors $2 / 6$ [29], DAXX [30], TRADD [31], RIP1 [32], and FADD [33]. And several cellular proteins, for example, thioredoxin [26], Hsp90 [34] and 14-3-3 [35] were also reported to interact with ASK1 and inhibit ASK1 activity. Here, we demonstrated that ASK1 was upregulated when claudin- 6 gene was transfected into MCF-7 cells (Figure 3). Therefore, the present study indicates that ASK1 signal participates in the pro-apoptosis function of claudin-6.

\section{Conclusions}

As a conclusion, our study suggests that the ASK1 expression is low in breast cancer, and the levels of ASK1 mRNA and protein expression are correlated with that of claudin-6. We have identified a novel mechanism responsible for the pro-apoptosis function of claudin-6, and ASK1 may become a target for breast cancer treatments. However, we still need further study to clarify the detail of this mechanism.

\section{Competing interests}

The authors declare that they have no competing interests.

\section{Authors' contributions}

$C Q, Y G$ and $X X$ carried out most of experiments, participated in the design of the study, performed the statistical analysis, and drafted the manuscript. $\mathrm{ZL}$, TZ and $X Z$ carried out part of experiments, and helped draft the manuscript. LW, MW, YL, YL and YL assisted the experiments. XX and $Y L$ helped to edit the paper. All authors have read and approved the final manuscript.

\section{Acknowledgements}

This study was supported by National Natural Science Foundation of China (Code: 81172499) and Science and Technology Development Plan of the Office of Science and Technology Project in Jilin Province (Code: 20100731).

\section{Author details}

${ }^{1}$ The Key Laboratory of Pathobiology, Ministry of Education, Beyuthune Medical College, Jilin University, Changchun, Jilin, China. ${ }^{2}$ Department of Pathology, The 2nd Affiliated Hospital of College of Medicine, Zhejiang University, Hangzhou, Zhejiang, China. ${ }^{3}$ Department of Thoracic Surgery, The First Bethune Hospital of Jilin University, Jilin University, Changchun, Jilin, China.

Received: 12 July 2012 Accepted: 20 August 2012

Published: 27 August 2012

\section{References}

1. Pagani O, Senkus E, Wood W, Colleoni M, Cufer T, Kyriakides S, Costa A, Winer EP, Cardoso F: International guidelines for management of metastatic breast cancer: can metastatic breast cancer be cured? J Natl Cancer Inst 2010, 102:456-463.

2. Hough CD, Sherman-Baust CA, Pizer ES, Montz FJ, Im DD, Rosenshein NB, Cho KR, Riggins GJ, Morin PJ: Large-scale serial analysis of gene expression reveals genes differentially expressed in ovarian cancer. Cancer Res 2000, 60:6281-6287.

3. Kominsky SL, Argani P, Korz D, Evron E, Raman V, Garrett E, Rein A, Sauter G, Kallioniemi OP, Sukumar S: Loss of the tight junction protein claudin-7 correlates with histological grade in both ductal carcinoma in situ and invasive ductal carcinoma of the breast. Oncogene 2003, 22:2021-2033.

4. Tsukita S, Furuse M, Itoh M: Multifunctional strands in tight junctions. Nat Rev Mol Cell Biol 2001, 2:285-293.

5. Matter K, Balda MS: Signaling to and from tight junctions. Nat Rev Mol Cell Biol 2003, 4:225-236.

6. Tsukita S, Furuse M: Occludin and claudins in tight-junction strands: leading or supporting players? Trends Cell Biol 1999, 9:268-273.

7. Mineta K, Yamamoto Y, Yamazaki Y, Tanaka H, Tada Y, Saito K, Tamura A, Igarashi M, Endo T, Takeuchi K, Tsukita S: Predicted expansion of the claudin multigene family. FEBS Lett 2011, 585:606-612.

8. Turksen K, Troy TC: Barriers built on claudins. J Cell Sci 2004, 117:2435-2447. 
9. Resnick MB, Konkin T, Routhier J, Sabo E, Pricolo VE: Claudin-1 is a strong prognostic indicator in stage II colonic cancer: a tissue microarray study. Mod Pathol 2004, 18:511-518.

10. Tzelepi VN, Tsamandas AC, Vlotinou HD, Vagianos CE, Scopa CD: Tight junctions in thyroid carcinogenesis: diverse expression of claudin-1, claudin-4, claudin-7 and occludin in thyroid neoplasms. Mod Pathol 2007, 21:22-30.

11. Ikari A, Sato T, Watanabe R, Yamazaki $Y$, Sugatani J: Increase in claudin-2 expression by an EGFR/MEK/ERK/c-Fos pathway in lung adenocarcinoma A549 cells. Biochim Biophys Acta 2012, 1823:1110-1118.

12. Gong Y, Renigunta V, Himmerkus N, Zhang J, Renigunta A, Bleich M, Hou J: Claudin-14 regulates renal $\mathrm{Ca}(+)(+)$ transport in response to CaSR signaling via a novel microRNA pathway. EMBO J 2012, 31:1999-2012.

13. Chiba K, Kondo Y, Yamaguchi K, Miyake H, Fujisawa M: Inhibition of Claudin-11 and Occludin Expression in Rat Sertoli Cells by Mono-(2Ethylhexyl) Phthalate Through p44/42 Mitogen-Activated Protein Kinase Pathway. J Androl 2012, 33:368-374.

14. Lu Z, Ding L, Hong H, Hoggard J, Lu Q, Chen YH: Claudin-7 inhibits human lung cancer cell migration and invasion through ERK/MAPK signaling pathway. Exp Cell Res 2011, 317:1935-1946.

15. Peter Y, Goodenough D: Claudins. Current biology: CB 2004, 14:R293-R294.

16. Carrozzino F, Pugnale $P$, Féraille $E$, Montesano R: Inhibition of basal p38 or JNK activity enhances epithelial barrier function through differential modulation of claudin expression. Am J Physiol Cell Physiol 2009, 297:C775-C787.

17. Oshima T, Miwa H, Joh T: Aspirin induces gastric epithelial barrier dysfunction by activating p38 MAPK via claudin-7. Am J Physiol Cell Physiol 2008, 295:C800-C806.

18. Ichijo H, Nishida E, Irie K, Dijke P, Saitoh M, Moriguchi T, Takagi M, Matsumoto K, Miyazono K, Gotoh Y: Induction of apoptosis by ASK1, a mammalian MAPKKK that activates SAPK/JNK and p38 signaling pathways. Science 1997, 275:90.

19. Choi HK, Chung KC: Dyrk1A Positively Stimulates ASK1-JNK Signaling Pathway during Apoptotic Cell Death. Exp neurobiol 2011, 20:35-44.

20. Quan C, Lu SJ: Identification of genes preferentially expressed in mammary epithelial cells of Copenhagen rat using subtractive hybridization and microarrays. Carcinogenesis 2003, 24:1593-1599.

21. Osanai M, Murata M, Chiba H, Kojima T, Sawada N: Epigenetic silencing of claudin-6 promotes anchorage-independent growth of breast carcinoma cells. Cancer Sci 2007, 98:1557-1562.

22. Wu Q, Liu Y, Ren Y, Xu X, Yu L, Li Y, Quan C: Tight junction protein, claudin-6, down regulates the malignant phenotype of breast carcinoma. Eur J Cancer Prev 2010, 19:186-194.

23. Won M, Park KA, Byun HS, Sohn KC, Kim YR, Jeon J, Hong JH, Park J, Seok $\mathrm{JH}, \mathrm{Kim} \mathrm{JM}$, et al: Novel anti-apoptotic mechanism of A20 through targeting ASK1 to suppress TNF-induced JNK activation. Cell Death Differ 2010, 17:1830-1841.

24. Xu X, Jin H, Liu Y, Liu L, Wu Q, Guo Y, Yu L, Liu Z, Zhang T, Zhang X, et al: The expression patterns and correlations of claudin-6, methy-CpG binding protein 2, DNA methyltransferase 1, histone deacetylase 1, acetyl-histone $\mathrm{H} 3$ and acetyl-histone $\mathrm{H} 4$ and their clinicopathological significance in breast invasive ductal carcinomas. Diagn Pathol 2012, 7:33.

25. Yafang $L$, Qiong W, Yue $R$, Xiaoming $X$, Lina $Y$, Mingzi Z, Ting Z, Yulin L, Chengshi Q: Role of Estrogen Receptor-alpha in the Regulation of Claudin-6 Expression in Breast Cancer Cells. J breast cancer 2011, 14:20-27.

26. Saitoh M, Nishitoh H, Fujii M, Takeda K, Tobiume K, Sawada Y, Kawabata M, Miyazono K, Ichijo H: Mammalian thioredoxin is a direct inhibitor of apoptosis signal-regulating kinase (ASK) 1. EMBO J 1998, 17:2596-2606.

27. Hatai T, Matsuzawa A, Inoshita S, Mochida Y, Kuroda T, Sakamaki K, Kuida K, Yonehara S, Ichijo $\mathrm{H}$, Takeda K: Execution of apoptosis signal-regulating kinase 1 (ASK1)-induced apoptosis by the mitochondria-dependent caspase activation. J Biol Chem 2000, 275:26576-26581.

28. Takeda K, Matsuzawa A, Nishitoh H, Tobiume K, Kishida S, Ninomiya-Tsuji J, Matsumoto K, Ichijo H: Involvement of ASK1 in Ca2\&plus;-induced p38 MAP kinase activation. EMBO Rep 2004, 5:161-166.

29. Noguchi T, Takeda K, Matsuzawa A, Saegusa K, Nakano H, Gohda J, Inoue J, Ichijo H: Recruitment of tumor necrosis factor receptor-associated factor family proteins to apoptosis signal-regulating kinase 1 signalosome is essential for oxidative stress-induced cell death. J Biol Chem 2005, 280:37033.
30. Chang HY, Nishitoh $H$, Yang $X$, Ichijo $H$, Baltimore D: Activation of apoptosis signal-regulating kinase 1 (ASK1) by the adapter protein Daxx. Science 1998, 281:1860-1863.

31. Morgan M, Thorburn J, Pandolfi PP, Thorburn A: Nuclear and cytoplasmic shuttling of TRADD induces apoptosis via different mechanisms. J Cell Biol 2002, 157:975-984.

32. Zhang $R$, Zhang H, Lin Y, Li J, Pober JS, Min W: RIP1-mediated AIP1 phosphorylation at a 14-3-3-binding site is critical for tumor necrosis factor-induced ASK1-JNK/p38 activation. J Biol Chem 2007, 282:14788-14796.

33. Juric V, Chen CC, Lau LF: TNFalpha-induced apoptosis enabled by CCN1/ CYR61: pathways of reactive oxygen species generation and cytochrome c release. PLoS One 2012, 7:e31303.

34. Zhang R, Luo D, Miao R, Bai L, Ge Q, Sessa WC, Min W: Hsp90-Akt phosphorylates ASK1 and inhibits ASK1-mediated apoptosis. Oncogene 2005, 24:3954-3963.

35. Zhang L, Chen J, Fu H: Suppression of apoptosis signal-regulating kinase 1-induced cell death by 14-3-3 proteins. Proc Natl Acad Sci U S A 1999, 96:8511-8515.

doi:10.1186/1746-1596-7-111

Cite this article as: Guo et al:: Apoptosis signal-regulating kinase 1 is associated with the effect of claudin- 6 in breast cancer. Diagnostic Pathology 2012 7:111.

\section{Submit your next manuscript to BioMed Central and take full advantage of:}

- Convenient online submission

- Thorough peer review

- No space constraints or color figure charges

- Immediate publication on acceptance

- Inclusion in PubMed, CAS, Scopus and Google Scholar

- Research which is freely available for redistribution

Submit your manuscript at www.biomedcentral.com/submit
C) Biomed Central 